\title{
Two-speed Synchronous Generator for Special Purposes
}

\author{
K. Čelić ${ }^{1}$, M. Pužar ${ }^{2}$ and S. Berberović ${ }^{3}$ \\ ${ }^{1}$ Ministry of Economy, Labour and Entrepreneurship, Energy and Mining Directorate \\ Ulica grada Vukovara 78, 10000 Zagreb (Croatia) \\ Phone: +38516109 607, fax: +38516109 113, e-mail: knistina.celic@mingorp.hr \\ ${ }^{2}$ Faculty of Electrical Engineering in Osijek \\ Kneza Trpimira 2B, 31000 Osijek (Croatia) \\ Phone: +385 31495 404, e-mail: milica.puzar@etfos.hr \\ ${ }^{3}$ Faculty of Electrical Engineering and Computing \\ Unska 3, 10000 Zagreb (Croatia) \\ Phone: +38516129 629, e-mail: sead.berberovic@,fer.hr
}

\begin{abstract}
This paper deals with basic performances of a design of a two-pole three-phase 40MVA synchronous generator. The generator is designed to test three-phase and single-phase high power transformers aimed to work within 50 $\mathrm{Hz}$ and $60 \mathrm{~Hz}$ network frequency. This means that the generator will operate at two nominal speeds, at $3000 \mathrm{rpm}$ and $3600 \mathrm{rpm}$, with nominal power of 40 Mvar induction load when rating with symmetrical three-phase load. The additional requirements relate to constant operation with two-phase 25 MVA load and single-phase 13.5 MVA load, since for testing single-phase and special transformers phase connection you like will be used. In the course of designing, special attention was paid to correct dimensioning of the damper rotor winding as well as to the geometry of stator windings, rotor and air gap, which in the end will produce minimum voltage wave distortion, i.e. generator voltage wave shape with harmonious content less than $1 \%$ (as it was demanded).
\end{abstract}

\section{Key words}

Synchronous generator, finite-element analysis, operating performance, stator damper winding

\section{Introduction}

Two-pole turbo generators are machines that already exist in the market in predefined typical power rates, whose values are primarily determined by the type and power of a turbine. Thus IEC 60034-3 with IEC 60034-1 additionally prescribes standard parameters for these generators, such as power factor, permitted deviation of voltage and frequency, alterations of output power depending on parameters of the primary cooling medium and similar. Two-pole $40 \mathrm{MVA}$ generator which is installed in the testing facility of a transformer plant should have satisfied the special operation conditions determined by requirements for testing of transformers prescribed by IEC 60076-1 and IEC 60076-6 standards.

It must satisfied performance such as two rated rotation speeds, voltage waveform distortion not higher than $1 \%$ (5\% according to IEC 60034-1), operation with unbalanced load with low vibrations on both speeds and noise level of $\max 90 \mathrm{~dB}(\mathrm{~A})$. Additional requirements were high number of starts and operation condition in wide temperature range.

In order to obtain power regulation, the generator is driven by an induction motor powered through frequency regulator. Losses of the generator should have been minimal taking into consideration that the selection of power of the induction motor and converter depended on them.

Taking into consideration the imposed requirements, a selection of the two-pole generator was a logical one. It has also been clear that this generator may not be selected among serial products of this kind.

\section{Selection of Dimensions of Generator Main Parts}

In order to power the generator with a full inductive load of 40 Mvar a field magneto motive force (MMF) of a standard three phase generator of approximately $60 \mathrm{MVA}$ is needed in case the power factor is within the range of usual 0.8-0.85 (IEC 60034-3). Also, due to the permanent asymmetric operation with the power of $25 \mathrm{MVA}$ the 
generator had to be designed with an inverse component of $36 \%$ nominal current. At standard generator this requirement ranges from the prescribed $8 \%$ (IEC 600341) to usually demanded $10 \%$. Due to the existence of the inverse field that, in respect to rotor, moves with a double speed in the opposite direction, electrical currents will be induced in the rotor. Requirement for work with a high inverse component of the stator current therefore additionally increases the rotor load.

In case of a generator which does not work on an independent net the air-gap is reduced to a selection of minimal dimensions necessary for assemblage of rotor, i.e. it is selected based on maximal diameter of rotor at the place of rotor heads. The requirement for minimal distortion affects the section of dimensions of the air-gap and number and dimensions of stator and rotor slots so that through magnetic permanence of the air-gap as few as possible content of higher harmonics are being introduced.

\section{A. Rotor of Generator}

A prediction of the adequate rotor characteristics will influence the economical design of the rest generator parts [1]. While designing the magnetic and electric loading of a two-speed rotor we must separate operating regimes that influence the heaviest loading of particular parts. Electric circuits at the rotor of a turbo generator may be divided into three groups:

\section{1) electric circuit of the field winding,}

2) electric circuit of the damper winding,

3) electric circuits of currents on the surface of a massive rotor, rotor slot wedges and rotor heads.

Loading the field winding will be the highest in the working regime with a nominal three-phase load and lower speed (40 MVA, $3000 \mathrm{rpm})$. At higher speed (3600 rpm) a weaker electro-magnetic field is needed for inducing nominal voltage. In cases of properly designed and optimized generators the difference of the field MMF is somewhat higher than $20 \%$, which affects a saturation of the magnetic circuit.

In case of an asymmetric work electric circuits close to air-gap and electric circuits of a damping winding are taken into consideration. An operation of the machine with a permanent asymmetric load may be secured only with a proper dimensioning of the damping winding. The impact of two speeds on electrical loading of the damper winding is considered through changes in the value of the synchronous reactance.

Reactance $x$ (1) of the generator, whether in a steady or transient state will depend on a geometry shown by the factor $k_{g}$, and on a ratio of electrical $A$ and magnetic load $B$ :

$$
x=k_{g} \frac{A}{B} .
$$

Loading and speed influences on the field MMF and the inverse component of armature MMF at two-phase loading are shown in Fig. 1.

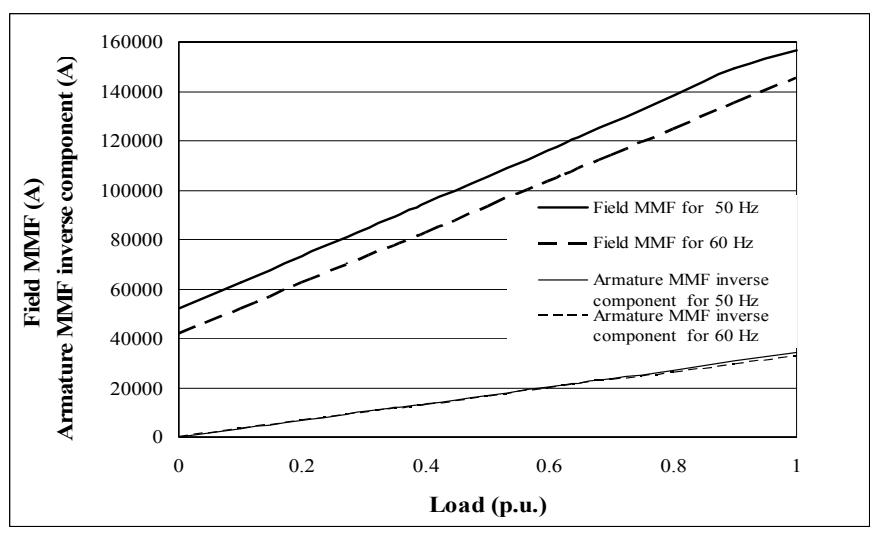

Fig. 1. Field MMF and inverse component of armature MMF at generator speeds of $3000 \mathrm{rpm}$ and $3600 \mathrm{rpm}$

\section{B. Stator of Generator}

The stator of this generator is designed and optimized in order to maintain external dimensions of a standard 40MVA turbo generator. This means that within the same generator dimensions with an increased diameter of the rotor the room for placing the stator core is reduced. However, besides minimal height of slots high values of the magnetic field were obtained in the stator yoke that may cause a sudden increase of leakage fluxes into construction parts of the stator frame and therefore a significant increase of losses. Besides, the prescribed demand for maintenance of the noise level demanded that all noise sources, and thus electromagnetic ones are strictly controlled. In order to minimize a leakage flux and losses at an increased field in the stator yoke, as well as some radial and axial forces that affect the stator armature and whose source is in electromagnetic field, a damper winding was built into the stator too.

Building in of a stator damper winding enabled diminishing the stator yoke height by $10 \%$.

\section{Selection of Number of Rotor and Stator Slots}

We may use classic calculations for calculation of harmonics in the field of air-gap and its elimination with a sufficient accuracy.

In Table I some harmonics in the field MMF are presented, for the chosen slot numbers $N_{r}=36$ and $N_{w}=24$.

TABLE I - Harmonics in Field MMF

\begin{tabular}{|l|c|c|c|c|c|}
\hline \multirow{2}{*}{ slot heights } & \multicolumn{5}{|c|}{ Harmonics } \\
\cline { 2 - 6 } & 1 & 5 & 7 & 11 & 13 \\
\hline $\begin{array}{l}\text { all slots of the } \\
\text { same height }\end{array}$ & 0.828 & -0.171 & 0.126 & -0.088 & 0.08 \\
\hline $\begin{array}{l}\text { end slots of a } \\
\text { smaller height }\end{array}$ & 0.831 & -0.176 & 0.089 & -0.055 & -0.022 \\
\hline
\end{tabular}


Table I shows that, pursuant to harmonics values in the field MMF, the fifth harmonic is accented. This is the reason why the selection of parameters of stator windings has to be such to cause appearance of a minimal content of the fifth harmonic in the armature MMF. However, the connection of the stator winding into triangle has to be taken into consideration.

For the stator winding a pole-pitch $Q=9$ slots and a winding-pitch $y=7$ are chosen. In this case the armature MMF has harmonics according to Table II.

TABLE II - Harmonics in Armature MMF

\begin{tabular}{|c|c|c|c|c|c|}
\hline \multirow{2}{*}{$\mathrm{y} / \mathrm{Q}$} & \multicolumn{5}{|c|}{ Harmonics } \\
\cline { 2 - 6 } & 1 & 3 & 5 & 7 & 9 \\
\hline $7 / 9$ & 0.8978 & -0.3199 & -0.0336 & -0.1074 & 0.2222 \\
\hline
\end{tabular}

An accurate calculation of the flux density in the air-gap after the selection of all main dimensions is obtained by application of Finite Element Method [2]. The harmonic content of the flux density curve in the air-gap is determined by Fourier analysis.

\section{Calculation of Currents in Rotor Damper Winding}

\section{A. Calculation of Inverse Component}

The cause that leads to inducing currents in the rotor is a difference of the rotor speed $\omega_{r}$ and the speed of a rotating magnetic field $\omega$. The difference between these speeds is shown through slip $s$. The slip $s$ is defined in the same manner as at induction machines [3] .

For an asymmetric current system, we can use the method of dividing into symmetrical components, which consists of a direct, an inverse and a zero system [4].

The currents $I_{1}, I_{2}, I_{0}$ of the direct, inverse and zero systems at a generator steady-state will be determined by the inductive reactances $x_{d}, x_{2}, x_{0}$. Using these reactances the equations (2) for the electromotive forces (EMF) of each phase may be written. Voltages of each phase at asymmetric loading are:

$$
\begin{aligned}
& \underline{U}_{U}=\underline{E}_{d}-j x_{d} \underline{I}_{1}-j x_{2} \underline{I}_{2}-j x_{0} \underline{I}_{0} \\
& \underline{U}_{V}=a^{2} \underline{E}_{d}-j x_{d} a^{2} \underline{I}_{1}-j x_{2} a \underline{I}_{2}-j x_{0} \underline{I}_{0} \\
& \underline{U}_{W}=a \underline{E}_{d}-j x_{d} a \underline{I}_{1}-j x_{2} a^{2} \underline{I}_{2}-j x_{0} \underline{I}_{0} \\
& a=e^{-j \frac{2 \pi}{3}}
\end{aligned}
$$

The first two items on the right side represent the internal EMF $E_{i}$ :

$$
\underline{E}_{i}=\underline{E}_{d}-j x_{d} \underline{I}_{1}
$$

For calculation of the reactance and the internal voltage it is important to know leakage fluxes in the generator. In transient operating regime, leakage fluxes create a magnetic inertia of the machine while in a steady state with asymmetries (such as two-phase and one-phase short circuits) they limited the values of short-circuit currents.

\section{B. Equivalent Circuits}

Parameters of a generator in a certain operation regime are analytically calculated using equivalent circuits of a generator for the two axes - direct (d-axis) and quadrature (q-axis). Basic parameters of equivalent circuits are measurable.

The dumper current calculation is based on a Kirchhoff loop network shown in Fig. 2. The rotor cross-section can be seen in Fig. 3.

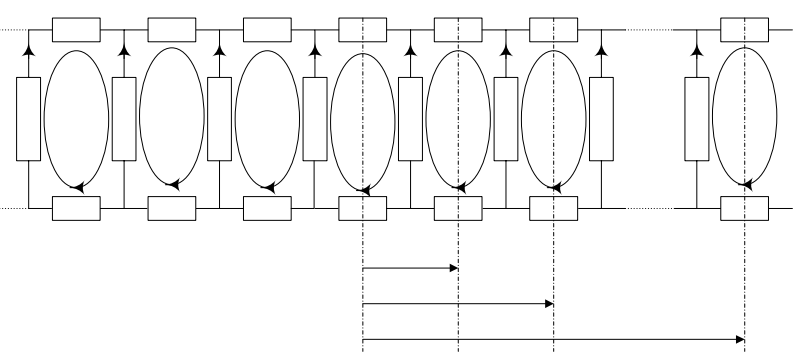

Fig. 2. Rotor damper winding impedance network

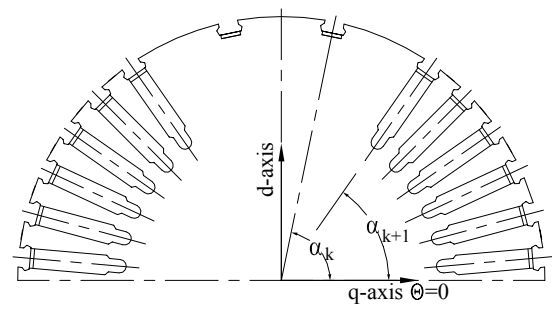

Fig. 3. Rotor cross-section with damper bar angular position

In Fig. 2. and Fig. 3. following symbols are used: $Z_{E}, Z_{E 1}$, $Z_{E p}$ - impedances of end ring, $Z_{B}, Z_{B P}$ - impedances of damper winding bars, $I_{1}-I_{N D}-$ currents in loops of $N_{D}$ bars of rotor damper winding, $\alpha_{1}-\alpha_{N D}-$ angles between $q$-axis and line of symmetry of $k$-current loop.

The impedance of a loop is created by frequency depending resistances of bars and short-circuit ring $\left(r_{B}\right.$ and $\left.r_{E x}\right)$ and leakage reactances of bars and short-circuit ring $\left(x_{l B}\right.$ and $x_{l E x}$ ), as well as a mutual inductance $M_{d i f}$ of rotor current loops which can be obtained from a flux in other loops when a current flows through one loop of a cage. Network parameters are calculated separately for each frequency.

The equations, written in a matrix form that corresponds to the equivalent impedance network are:

$$
0=\mathbf{R}_{r} \mathbf{i}_{r}+\frac{d \boldsymbol{\psi}_{r}}{d t}
$$

Vectors of rotor variables in the transposed form are: 


$$
\left(\mathbf{f}_{r}\right)^{T}=\left[\begin{array}{llll}
f_{1} & f_{2} & \ldots & f_{N D}
\end{array}\right]
$$

where $f$ may be a short-circuit ring current or the flux of a rotor current loop, and $\mathbf{R}_{r}$ is the matrix of the squirrelcage resistance in which resistances $r_{B}$ and $r_{E x}$ are contained.

The matrix of rotor fluxes $\psi_{r}$, expressed by using matrixes of inductances and currents is:

$$
\boldsymbol{\psi}_{r}=\mathbf{L}_{r} \mathbf{i}_{r}+\mathbf{L}_{r s} \mathbf{i}_{s}=\boldsymbol{\psi}_{r r}+\boldsymbol{\psi}_{r s}
$$

where $L_{r}$ the matrix of rotor winding inductances $\left(L_{l B}\right.$, $\left.L_{l E x}, M_{d i f}\right)$ and $L_{r s}$ the matrix of inductances between stator and rotor winding are.

In case of determination of an equation for vector of rotor fluxes, contributions of currents in a three-phase stator winding with $\psi_{r s}$ and contribution of currents in damping winding with $\psi_{r r}$ are observed separately, and finally the superposition is applied. The flux of any current loop $\psi_{k}$ is calculated through the density of a flux $B$ along one slot-pitch of the damper winding using a permanence model [5].

Therefore, if we know the flux density wave $(B)$ we may determine the linked flux $\psi_{k}$ of each loop. With the defined $B$ and calculation of the flux and with known values of equivalent circuit parameters, the resistances and reactances, we may obtain induced voltages, i.e. currents in circuits from Fig. 2. This calculation may be obtained by classic calculation method taking into consideration that the flux density wave in the air-gap is known.

\section{Calculation of Currents in Stator Damper Winding}

Stator damper winding Fig. 4. may be presented with the equivalent circuit shown in Fig. 5.

a)

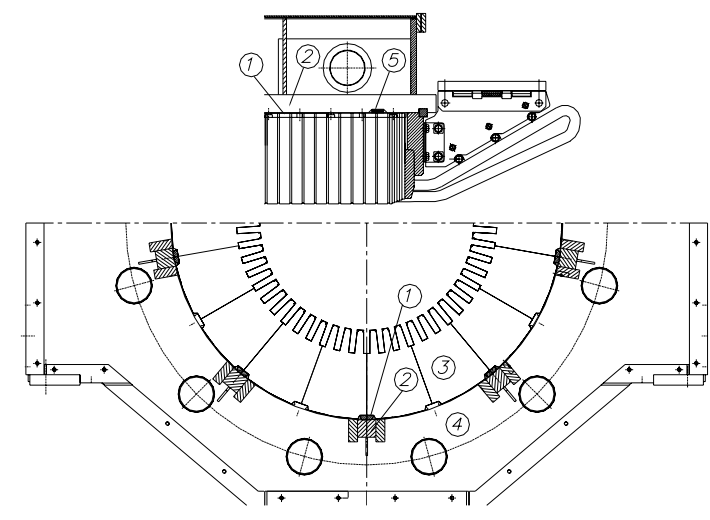

b)

Fig. 4. Geometry of stator damper winding

a) longitudinal half-section, b) cross half-section,

1- dovetail bar, 2 - frame steel bar, 3 - stator yoke, 4 frame, 5 - end ring.

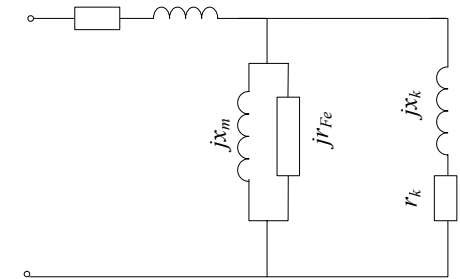

Fig. 5. Equivalent circuit of stator damper winding

The elements of this circuit show that, regardless of knowledge of parameters of the field and damper winding (given by $r_{f}, x_{f}, r_{k}, x_{k}$ ) and magnetic conductivity of air-gap (given by $x_{m}$ ) we may not calculate the resistance of iron $r_{F e}$ in the length to the outer diameter of the stator yoke.

The stator damper winding impedance network is similar to the rotor damper winding network, shown in Fig. 2. For equated system of matrix equations:

$$
\left.\begin{array}{l}
0=\mathbf{R}_{k} \mathbf{i}_{k}+\frac{d \boldsymbol{\psi}_{k}}{d t} \\
\boldsymbol{\Psi}_{k}=\mathbf{L}_{k} \mathbf{i}_{k}+\mathbf{L}_{k f} \mathbf{i}_{f}
\end{array}\right\}
$$

we may not determine the flux $\psi_{k}$ in a current loop between two bars of the damper winding that close angles $\beta_{k}$ and $\beta_{k+1}$ due to the fact that the flux density weave $(B)$ close to the damper winding is unknown. This field, as well as the fluxes, may be determined only by using a numerical method.

\section{Finite-Element Modeling}

Numerical calculations were used for verification of results obtained by a classic analytic method. The values of reactances were estimated by the approach described in [6] and [7]. For calculations of no-load curve, shortcircuit curve and reactances a standard one-pole 2D model can be used. The three-dimensional effects were included by using end-winding leakage reactances and end-winding resistances as external circuit parameters.

Due to an odd number of bars in the stator damper winding a two-pole model is required for the calculation of induced currents in that winding.

Fig. 6. shows the field distribution in a dynamic simulation in no-load regime at $t=5 \mathrm{~ms}$ when the stator damper winding is open, while Fig. 7. shows the field distribution in the same conditions with the stator damper winding short circuited. We can see that induced currents in the damper bars push field into the stator yoke.

The damper winding current in the bar No. 1 which is placed in $y$-axis is shown in Fig. 8. The currents in the other bars are of the same magnitude but with phase-shift which depends on the number of the damper winding bars $N_{D S}$ :

$$
\gamma=2 \pi / N_{D S}
$$




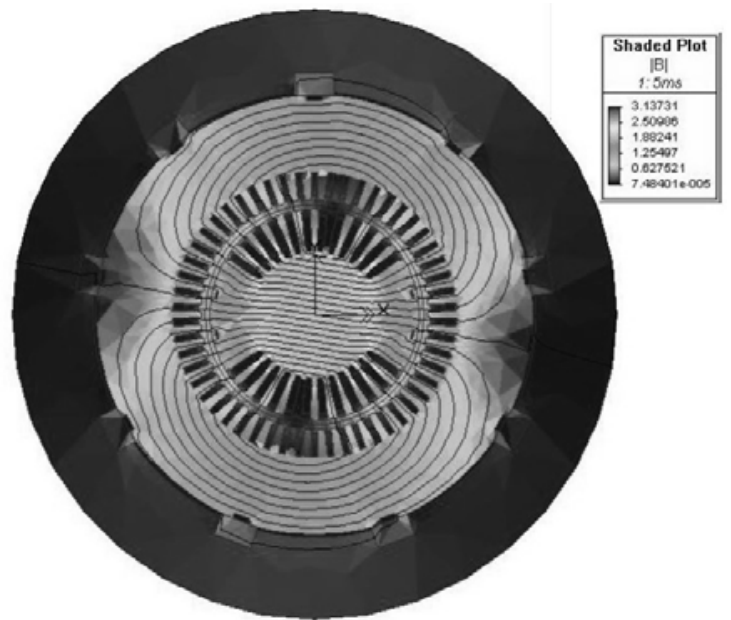

Fig. 6. Field distribution at $t=5 \mathrm{~ms}$ with open damper winding, $50 \mathrm{~Hz}$.

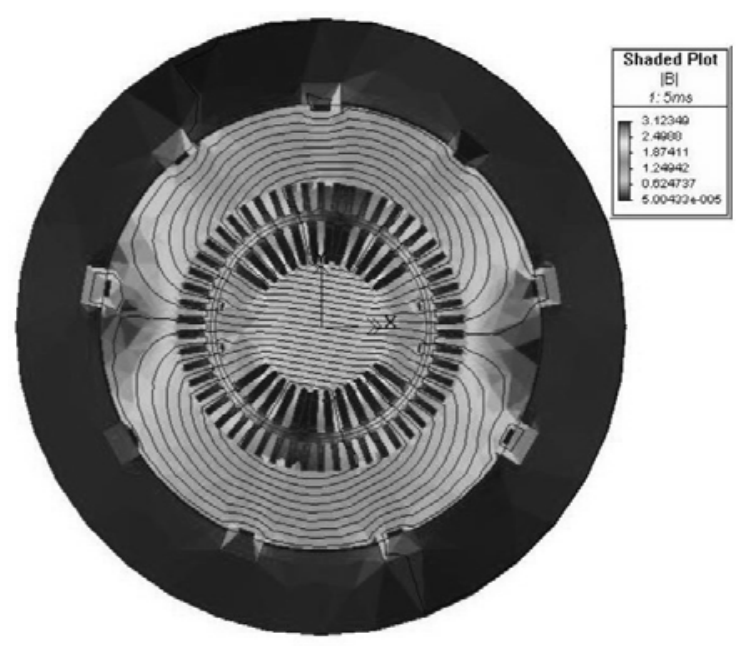

Fig. 7. Field distribution at $t=5 \mathrm{~ms}$ for short-circuit damper winding, $50 \mathrm{~Hz}$.

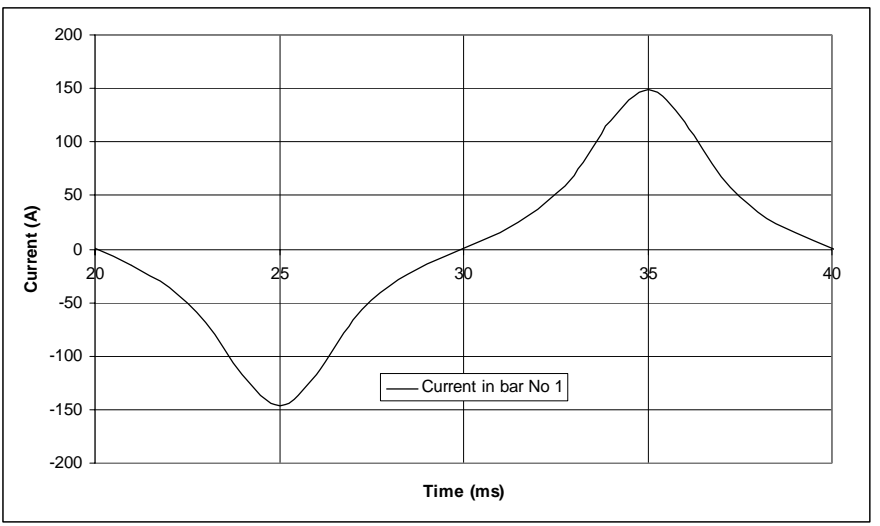

Fig. 8. Current in bar No. 1 placed into $d$-axis.

\section{Measurement Results}

Generator operating ranges, shown by a capability diagram in Fig. 9., is confirmed by measurements. This capability curves are in accordance with the requirements. The capability diagram is valid for star connection of the stator winding with the voltage level of $10000 \mathrm{~V}$ and delta connection with the voltage level of $10000 / \sqrt{3}$ V. Dash-dot line marks the area for 25 MVA in delta connection for a symmetrical three-phase load. Also dashed line bounds the area of an achievable operation condition.

Operation ranges for transformer testing can be extended to an operation with an active power of $4 \mathrm{MW}$ due to the low level of losses, realized in the generator. So, the $5 \mathrm{MW}$ motor is able to cover all losses of the generator and remaining part of the testing circuit and the maximal testing power of the transformer of approximately $4 \mathrm{MW}$.

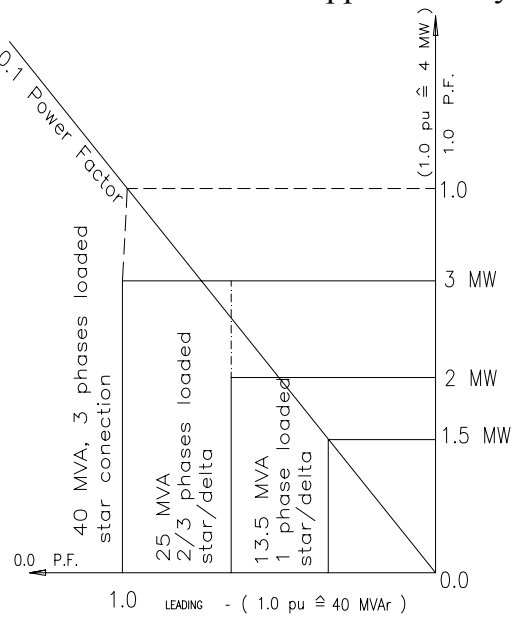

Fig. 9. Capability diagram of two-speed 40 MVA generator.

In Table III measured losses are shown by the place of their origin.

TABLE III - Measured Losses

\begin{tabular}{|c|c|c|c|c|c|c|}
\hline & $\begin{array}{c}P_{d m e c} \\
(\mathrm{~kW})\end{array}$ & $\begin{array}{c}P_{F e} \\
(\mathrm{~kW})\end{array}$ & $\begin{array}{c}P_{C u} \\
(\mathrm{~kW})\end{array}$ & $\begin{array}{c}P_{d f} \\
(\mathrm{~kW})\end{array}$ & $\begin{array}{c}\sum P_{d} \\
(\mathrm{~kW})\end{array}$ & $\begin{array}{c}\eta \\
(\%)\end{array}$ \\
\hline $50 \mathrm{~Hz}$ & 294.514 & 70 & 208 & 130 & 702.51 & 98.274 \\
\hline $60 \mathrm{~Hz}$ & 414.06 & 80 & 269 & 110 & 873.06 & 97.863 \\
\hline
\end{tabular}

The used symbols in TABLE III are:

$P_{d m e c}=$ mechanical losses, $P_{F e}=$ losses in stator core, $P_{C u}$ $=$ losses in stator armature winding, $P_{d f}=$ losses in field winding, $P_{d}=$ total losses, $\eta=$ efficiency.

The achieved efficiency is only about $0.4 \%$ lower than the efficiency of a standard generator of the same power. The mechanical losses are enlarged due to a larger diameter of the rotor body, but losses in stator core are in limits of the standard type generator losses.

The line-to-line voltage has been measured at voltage transformers secondary terminals, at no-load and 3000 rpm. The line-to-line voltage deviation factor has been determined according to IEEE 115 and calculated using following equation:

$$
F_{d e v}=\frac{\Delta U_{\max }}{U_{0}}=0.0058 \rightarrow F_{d e v}=0.58 \%,
$$

where $U_{0}$ is the amplitude of an equivalent sine wave, 
and $\Delta U_{\max }$ is the maximum value between an actual and equivalent wave voltage

Fig. 10. and Fig. 11. show no-load and short-circuit characteristics measured for $50 \mathrm{~Hz}$ and $60 \mathrm{~Hz}$. The measured ratios $k_{x d s}$ (of the saturated synchronous reactance) and $\mathrm{k}_{\mathrm{xd}}$ (of the unsaturated synchronous reactance) in $d$-axis for $50 \mathrm{~Hz}$ and 60 are:

$$
\begin{aligned}
& k_{x d s}=\frac{x_{d s 60}}{x_{d s 50}}=\frac{253.2}{206.7}=1.225 \\
& k_{x d}=\frac{x_{d 60}}{x_{d 50}}=\frac{257.3}{217.6}=1.182 .
\end{aligned}
$$

These values are in accordance with designed parameters.

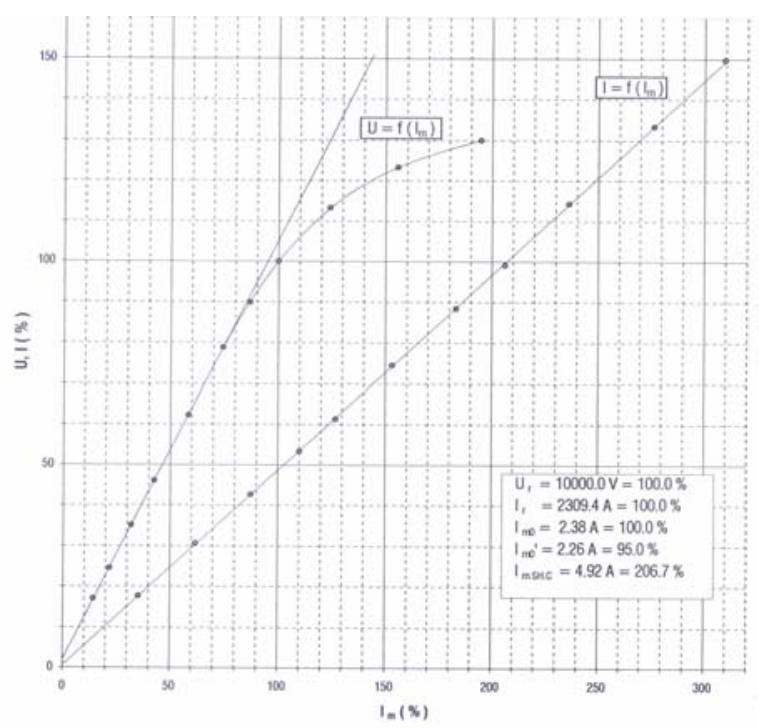

Fig. 10. No-load and three-phase sustained shortcircuit characteristic for $50 \mathrm{~Hz}$.

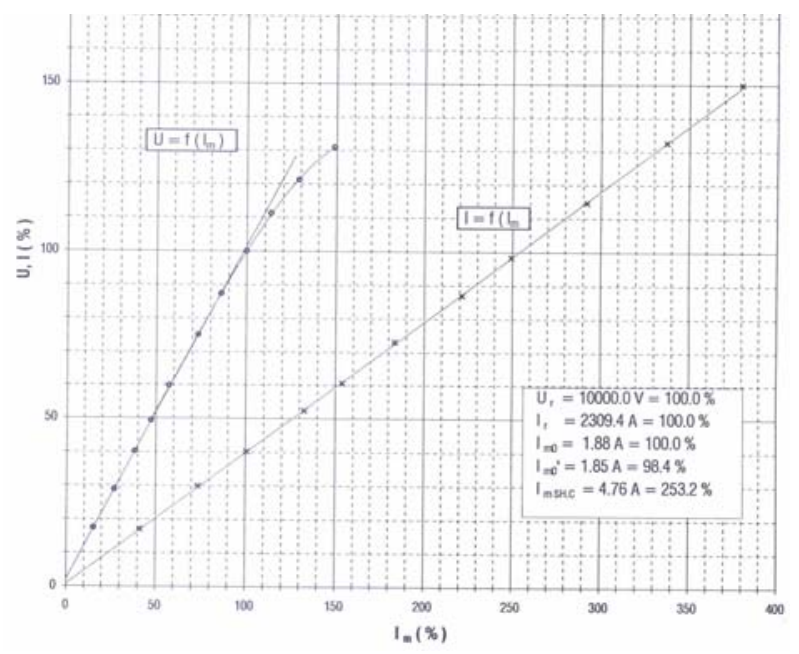

Fig. 11. No-load and three-phase sustained shortcircuit characteristic for $60 \mathrm{~Hz}$.

The difference of the field current (in absolute value) for $50 \mathrm{~Hz}$ and $60 \mathrm{~Hz}$ which will induce a current of $1.444 \mathrm{~A}$ in the stator winding during a three-phase short-circuit is in accordance with designed value shown in Fig. 1.

The leakage reactance $x_{\sigma}$ measured at $50 \mathrm{~Hz}$ is relatively low $\left(x_{\sigma}=10.73 \%\right)$ and adequate to a standard high efficiency generator. The measured values of the negative sequence reactance $x_{2}$ at $50 \mathrm{~Hz}$ and $60 \mathrm{~Hz}$ are:

$$
\begin{aligned}
& x_{2_{50 \mathrm{~Hz}}}=28 \% \\
& x_{2_{60 \mathrm{~Hz}}}=31.91 \%
\end{aligned}
$$

As the influence of a ratio between current and magnetic loading on the negative sequence reactance is lower than on the synchronous reactance, these values are the result of the geometry of the rotor damper winding. High magnitudes of a negative sequence reactance are the consequence of high values of the rotor damper winding leakage field which at the end limited sudden two and single phase short circuit currents.

\section{Conclusion}

This paper discusses how to select and optimize dimensions of a two-speed two-pole generator designed for special working conditions such as facilities in which energy transformers of highest power are tested. Building in the damping winding enables construction of a machine of external dimensions, equal to those of a typical 40MVA generator. An adjusted rotor, designed for high inverse loads, is placed in the machine. The obtained generator characteristics confirm proper dimensioning. The measured values of heating confirm the calculated current of the inverse regime of operation and currents of damper windings. The effect of building in a stator damper winding is especially significant. The methodology of selecting the number of bars in the stator damper winding, their dimensioning and impact on reducing electromagnetic noise, additional losses and field vector are all subjects of further research.

\section{References}

[1] K. Čelić, "Domestic air cold turbine generators 80 MVA for TE-TO Zagreb", $5^{\text {th }}$ HK CIGRE, Cavtat 2001.

[2] Z. Haznadar and Ž. Štih, "Elektromagnetizam", Školska knjiga Zagreb 1997.

[3] R. Wolf, "Osnove električnih strojeva", Školska knjiga Zagreb, 1995.

[4] M. Jadrić and B. Frančić, "Dinamika električnih strojeva", Graphis, Zagreb 1997.

[5] H.Karmaker: "Combined Analytical and Finite element Modeling for Negative Sequence Studies in Salient Pole Synchronous Machines, IEEE Transactions, 2002

[6] Z. Maljković, D. Žarko and K.Čelić-Baran, "The Application of Finite Element Method for More Accurate Calculation And Analysis of Turbo generator Parameters, Manufacture in Modern Industry", 3rd International Conference Design to manufacture in modern industry, Portorož,1997.

[7] D. Ban, D. Žarko and I. Mandić, "Turbo generator End Winding Leakage Inductance Calculation Using a 3-D Analytical Approach Based on the Solution of Neumann Integrals", IEEE Transactions on Energy Conversion, 2005, Vol. 20, 98-105. 